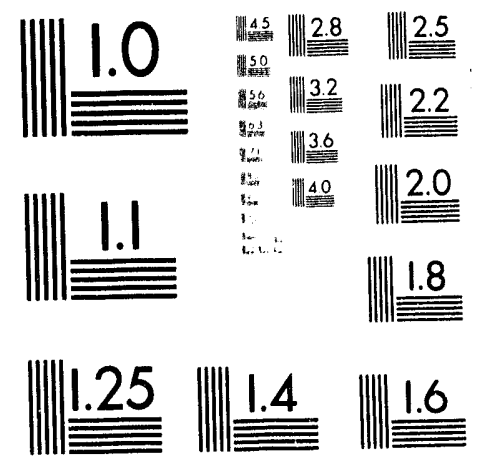



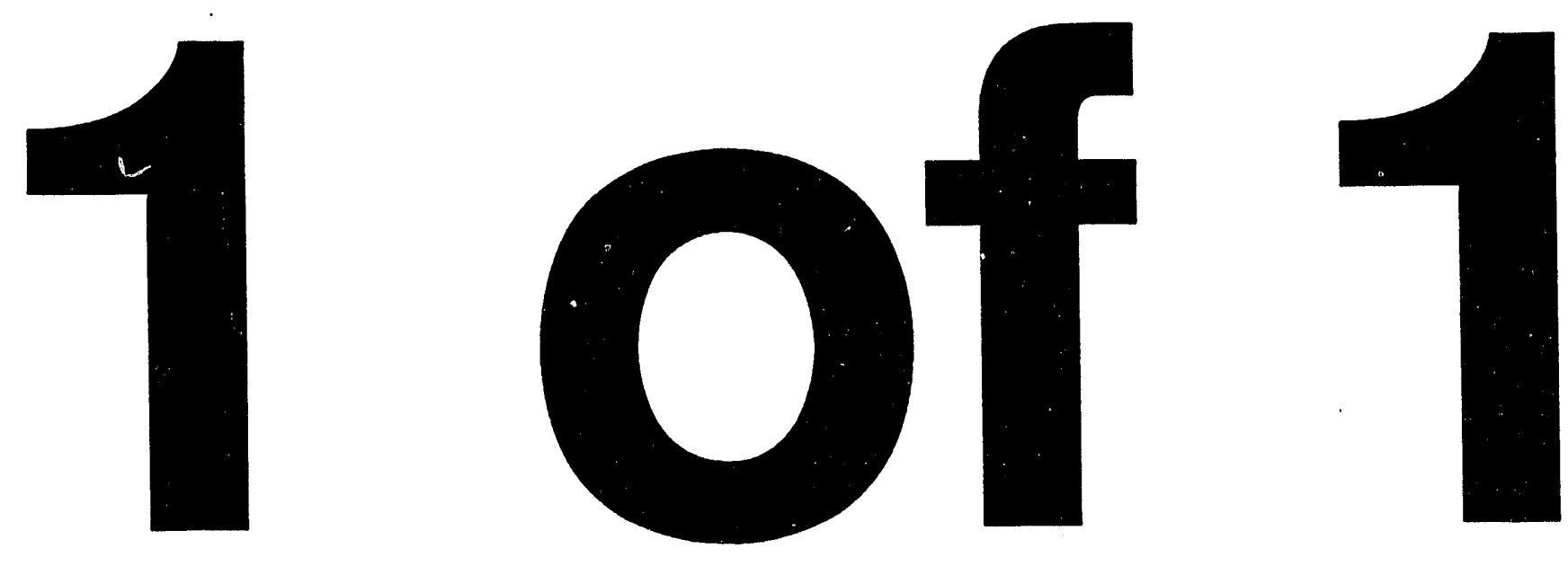
LBL 34018

\title{
GROWTH OF SMALL FATIGUE CRACKS IN INCOLOY-908
}

\author{
Z. Mei, C. Krenn and J. W. Morris, Jr. \\ Center for Advanced Materials \\ Materials Sciences Division \\ Lawrence Berkeley Laboratory \\ University of California \\ Berkeley, CA 94720 \\ and \\ Department of Materials Science and Mineral Engineering \\ University of California
}

July 1993

This work was supported by the Director, Office of Energy Research, Office of Basic Energy Science, Materials Science Division of the U.S. Department of Energy under Contract No. DE-AC03-76F00098 


\title{
GROWTH OF SMALL FATIGUE CRACKS
}

\section{IN INCOLOY-908}

\author{
Z. Mei, C. Krenn, and J.W. Morris, Jr. \\ Center for Advanced Materials, Lawrence Berkeley Laboratory and \\ Department of Materials Science and Mineral Engineering \\ University of California, Berkeley, CA 94720
}

\section{INTRODUCTION}

Incoloy-908 was designed ${ }^{1}$ as a structural alloy for the conduit of cable-in-conduit superconductors. The conduit is a thin-wall tube that encloses superconducting cables. Since the conduit may be as thin as 3 to $12 \mathrm{~mm}$ in thickness and is subject to cyclic loads, fatigue crack growth behavior at liquid helium temperature, especially in the small crack regime, is a critical issue for magnet design. Because it is very difficult to perform small fatigue crack propagation tests at $4.2 \mathrm{~K}$, we have studied the mechanisms of small crack propagation at room temperature and $77 \mathrm{~K}$, and use the results to propose a feasible method for estimating small crack propagation at $4.2 \mathrm{~K}$

Recent results on the propagation of surface fatigue cracks ${ }^{2-4}$ show that the constitutive relations that govern long cracks become invalid when the crack size is small; small cracks often grow faster than long cracks at the same nominal cyclic stress intensities, and may propagate at cyclic stress intensities below the long-crack threshold. Several mechanisms for the anomalous growth of small cracks are described in recent reviews. ${ }^{5-7}$ (1) Crack closure that lowers the driving force for long-crack propagation is absent or reduced when the crack is very short. (2) When the crack size becomes comparable to the scale of local plasticity, the small-scale yield assumption that underlies the application of linear elastic fracture mechanics becomes invalid. (3) When the crack size is small compared to the relevant microstructural dimensions, the assumption that the crack grows in a homogeneous, isotropic continuum is no longer held.

The approach taken in this study resembles that in our previous work on A286 steel. ${ }^{8}$ We measured and compared fatigue crack growth rates in (1) conventional long-crack growth tests at constant load-ratio (R), (2) long-crack growth tests at constant maximum stress intensity $\left(\mathrm{K}_{\max }\right)$, the method proposed by Herman, Hertzberg, and Jaccard ${ }^{9}$ to determine the long crack growth rates under closure-free conditions to simulate short crack propagation, and (3) direct observations of the propagation of very small surface cracks. The main results are summarized here; a complete description of our research on this subject will be published elsewhere. 10 


\section{EXPERIMENT}

As-received alloy plates were given the following thermomechanically treatment before mechanical testing: cold work $20 \%, 200^{\circ} \mathrm{C}$ for 24 hours, $340^{\circ} \mathrm{C}$ for 48 hours, $660^{\circ} \mathrm{C}$ for 72 hours, $725^{\circ} \mathrm{C}$ for 12 hours, and furnace cool. This treatment mimics that experienced by the alloy when it is used as the conduit for a cabled superconductor of multifilamentary $\mathrm{Nb}_{3} \mathrm{Sn}$ wire. The microstructure of the alloy after the thermomechanical treatment consisted of a $\gamma(F C C)$ matrix with an average grain size about $65 \mu \mathrm{m}$, with randomly distributed (Nb,Ti)C carbide particles of about $2-5 \mu \mathrm{m}$ size. The alloy also contains $\gamma$-precipitates, $\mathrm{Ni}_{3}\left(\mathrm{Ti}, \mathrm{Al}\right.$ ), spherical particles with the size less than $50 \mathrm{~nm} .^{1}$ The tensile properties (Table I) of the alloy plates used for this study were determined at both $298 \mathrm{~K}$ and $77 \mathrm{~K}$, and are consistent with previous results. ${ }^{11}$

The fatigue crack growth rates of "long" cracks were measured using the procedures recommended in refs. 12 and 13 . The crack length was measured continuously, using the direct-current electrical potential method. The extent of crack closure during fatigue crack growth was monitored by the "back-face strain gage" technique. The near-threshold crack growth rates are measured with the " $\Delta \mathrm{K}$-shedding procedure". In the constant $\mathrm{R}\left(=\mathrm{K}_{\mathrm{min}} /\right.$ $\left.\mathrm{K}_{\max }\right)$ tests, $\Delta \mathrm{K}\left(=\mathrm{K}_{\max }-\mathrm{K}_{\min }\right)$ is reduced by lowering both $\mathrm{K}_{\max }$ and $\mathrm{K}_{\min }$ while holding $R$ constant; in the constant $K_{\max }$ test, $\Delta \mathrm{K}$ is reduced by increasing $\mathrm{K}_{\min }$ while keeping $\mathrm{K}_{\max }$ constant.

The specimens for small crack growth were square bars with cross section of about 8 x $10 \mathrm{~mm}$ and gauge length of about $20 \mathrm{~mm}$. Specimens were mechanically polished and lightly etched to reveal grain boundaries, before tested under four-point bending. The load ratio $R$ was about 0.05 . The tests were interrupted periodically, and the specimens were examined under an optical microscope or replicas were made of specimen surface. The stress intensity in the length and depth directions were computed from the solution of Newman and Raju. ${ }^{14}$

Table I. Tensile properties of Incoloy-908 tested in this study at 298 and $77 \mathrm{~K}$

\begin{tabular}{lcccc}
\hline & $\begin{array}{c}\text { Yield } \\
(\mathrm{MPa})\end{array}$ & $\begin{array}{c}\text { Ultimate Strength } \\
(\mathrm{MPa})\end{array}$ & $\begin{array}{c}\text { Uniform Elongation } \\
(\%)\end{array}$ & $\begin{array}{c}\text { Total Elongation } \\
(\%)\end{array}$ \\
\hline $298 \mathrm{~K}$ & 1227 & 1448 & 8.4 & 17.9 \\
$77 \mathrm{~K}$ & 1332 & 1709 & 23.2 & 32.6 \\
\hline
\end{tabular}

\section{RESULTS}

\section{A. Long Crack Propagation}

Fig. 1(a) includes plots of the long-crack growth rate da/dN vs. cyclic stress intensity range, $\Delta K$, determined at both $298 \mathrm{~K}$ and $77 \mathrm{~K}$, for the conditions of constant $R(=0.05)$ and constant $\mathrm{K}_{\max }\left(=32 \mathrm{MPa} \sqrt{\mathrm{m}}_{\mathrm{m}}\right.$ ). The Paris region of the crack growth curve was fit to the constitutive equation, $\mathrm{da} / \mathrm{dN}=\mathrm{A} \Delta \mathrm{K}^{\mathrm{m}}$. The values of $\mathrm{A}$ and $\mathrm{m}$, and the threshold cyclic stress intensity, $\Delta \mathrm{K}_{\text {th }}$ are listed in Table $\Pi$.

The curves given in Fig. 1(a) show that the crack growth behavior is different at RT and LNT, especially at the threshold region. Liaw 15 also observed this phenomenon in $\mathrm{Cu}$, stainless steels and other engineering materials, and attributed the effect to the larger rough 
Table II. Threshold stress intensity ranges and Paris Law constants

\begin{tabular}{lccc}
\hline & $\begin{array}{c}\Delta \mathrm{K}_{\text {th }} \\
(\mathrm{MPa} \sqrt{\mathrm{m}})\end{array}$ & $\begin{array}{c}\text { Paris-Law parameters } \\
\mathrm{A}(\mathrm{mm} / \text { cycle })\end{array}$ & $\mathrm{m}$ \\
\hline $\mathrm{LNT}, \mathrm{K}_{\max }=32$ & 4.0 & $5.301 \times 10^{-9}$ & 3.0961 \\
LNT, $\mathrm{R}=0.05$ & 7.0 & $4.198 \times 10^{-11}$ & 4.6842 \\
$\mathrm{RT}, \mathrm{K}_{\max }=32$ & 2.8 & $3.360 \times 10^{-8}$ & 2.4941 \\
RT, R=0.05 & 4.5 & $3.360 \times 10^{-8}$ & 2.4941 \\
\hline
\end{tabular}

ness-induced crack closure at the lower testing temperatures. However, crack closure cannot be the only reason for the temperature effect in Incoloy-908 because the closure-free crack growth rates (from the constant $K_{\max }$ tests) is different at RT and LNT. Yokobori ${ }^{16}$ suggested a thermally activated dislocation model to explain the low temperature effect on $\Delta K_{\text {th }}$. His model can qualitatively explain the phenomenon in Incoloy-908, but we have not attempted a quantitative fit since that would require crack growth rate data at several temperatures.

The difference in da/dN between constant $R$ and constant $K_{\max }$ tests can be explained by the influence of crack closure on the effective cyclic stress intensity, ${ }_{17}$

$$
\begin{array}{ll}
\Delta \mathrm{K}_{\text {eff }}=\mathrm{K}_{\max }-\mathrm{K}_{\min } & \text { when } \mathrm{K}_{\min } \geq \mathrm{K}_{\mathrm{cl}} \\
\Delta \mathrm{K}_{\mathrm{eff}}=\mathrm{K}_{\max }-\mathrm{K}_{\mathrm{cl}} & \text { when } \mathrm{K}_{\min }<\mathrm{K}_{\mathrm{cl}}
\end{array}
$$

In Fig. 1(b) the open circles and triangles are data points re-plotted from Fig. 1(a) for da/dN at LNT for constant $R(=0.05)$ and constant $K_{\max }$, respectively. The crack growth rates at $\mathrm{R}=0.05$ are plotted again as closed circles against $\Delta \mathrm{K}_{\text {eff }}$ in Fig. 1 (b). It is seen that the $\mathrm{da} / \mathrm{dN}$

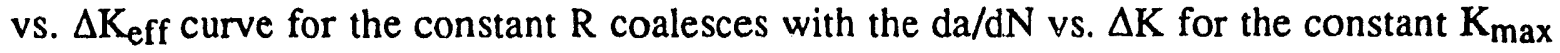
curve, which confirms that the da/dN data during the constant $K_{\max }$ test are essentially closure-free.

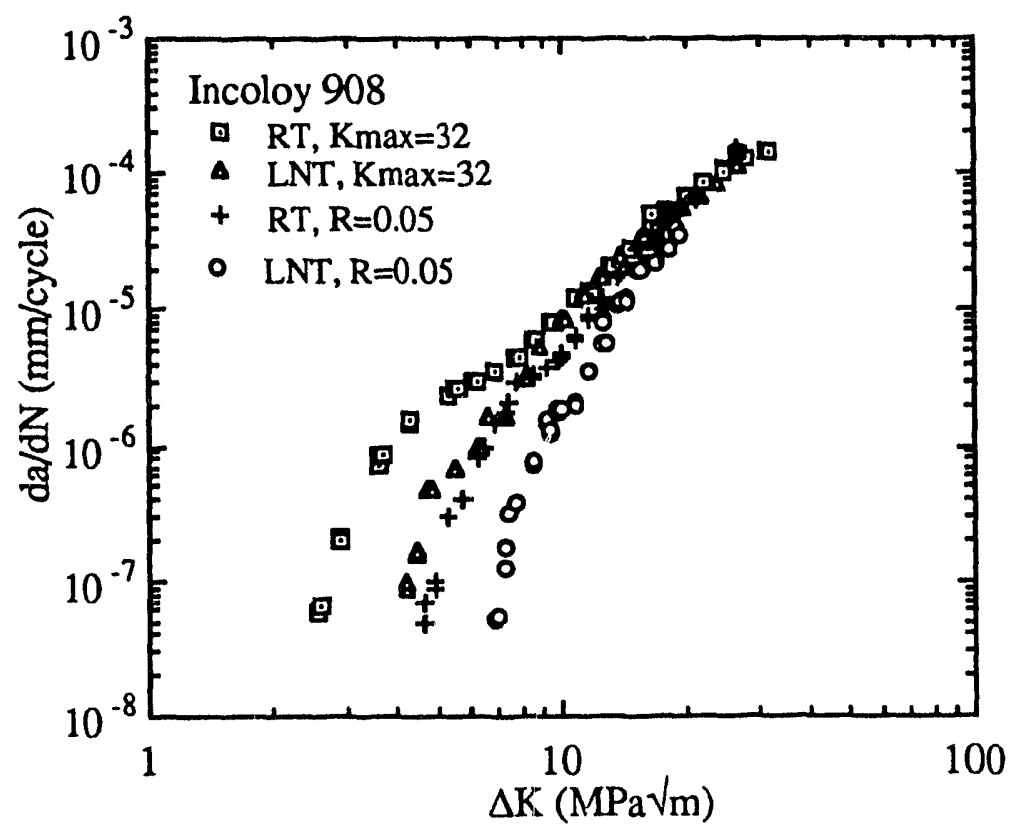

Fig. 1(a): Plots of the long-crack growth rate $\mathrm{da} / \mathrm{dN}$ vs. cyclic stress intensity range, $\Delta \mathrm{K}$, determined at both $298 \mathrm{~K}$ (RT) and $77 \mathrm{~K}$ (LNT), for the conditions of constant load-ratio $R(=0.05)$ and constant $\mathrm{K}_{\max }\left(=32 \mathrm{MPa} \vee_{\mathrm{m}}\right.$. 


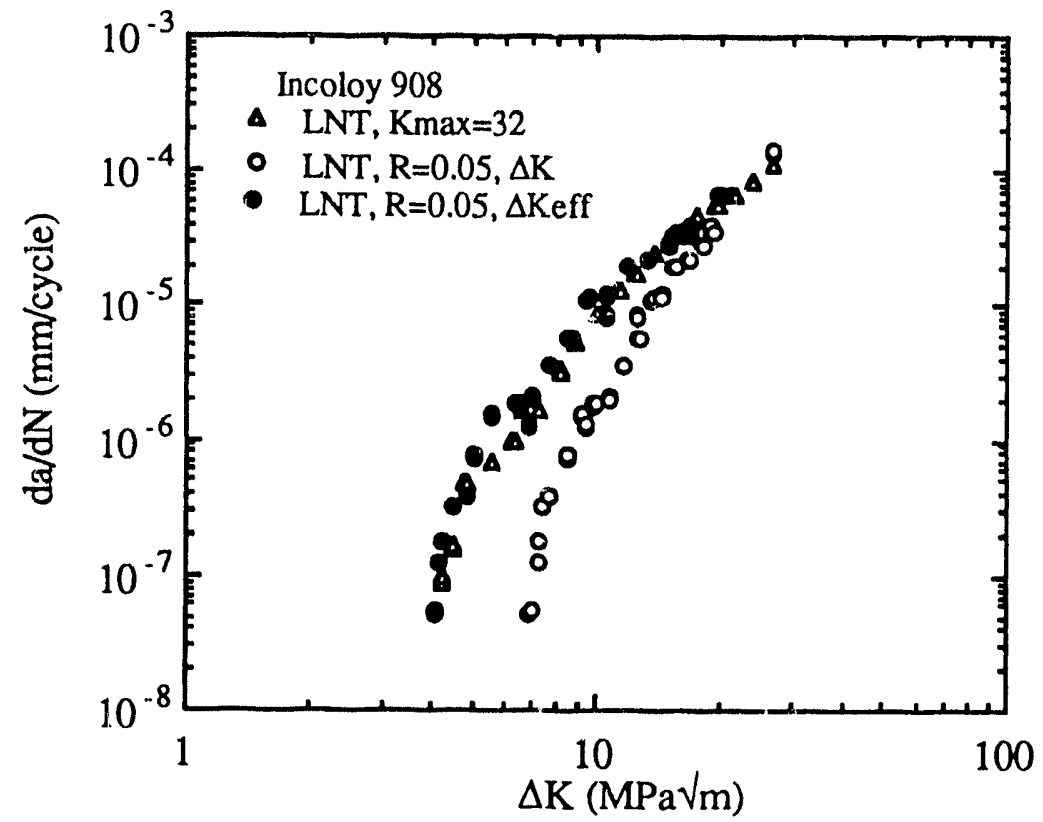

Fig. 1(b): The open circles and triangles are data points re-plotted from Fig. 1(a). The crack growth rates at $\mathrm{R}=0.05$ are plotted again as closed circles against $\Delta \mathrm{K}_{\text {eff }}$.

\section{B . Small Crack Propagation}

Most smali cracks were observed to initiate at surface or subsurface inclusions, especially inclusions of large size. 10 Many of them ceased to grow after extension to grain boundaries. The propagation of those that continued to grow will be described from three perspectives: the growth of single cracks, the simultaneous growth of many cracks, and the dependence of the threshold cyclic stress and cyclic stress intensity on the crack length.

Growth of a Single Crack. Fig. 2(a) plots the length of a small surface crack as a function of cycle number from its initiation to its extension into the long crack regime, in a specimen where the stress at the top surface oscillated between 38 and $759 \mathrm{MPa}\left(=62 \% \sigma_{\mathrm{y}}\right)$ at RT. This crack, labeled as \#5 in Fig. 2(a), originated from the combination of two smaller cracks, \#3 and \#4. Crack \#3 in turn was produced by joining of two smaller cracks \#1 and \#2. It is seen that when cracks were small, their propagation was discontinuous.

The discontinuities in crack growth were most of ten associated with impingement on grain boundaries. Within grains, cracks propagated in particular crystallographic directions. When a crack became longer, visible slip lines formed parallel to it. When a crack crossed a grain boundary, it often stopped before extending along a new direction in the next grain, especially when the new direction is significantly angled to the original direction. The principal source of discontinuous crack growth appears to be the decreased stress intensity that drives the inclined crack in the new grain. ${ }^{18-20}$ There may also be a slight tearing at the grain boundary that blunts the crack and stops it there.

Fig. 2(b) show the crack growth rate of the cracks of Fig. 2(a) as a function of the cyclic stress intensity, and compares it to the long crack growth rate plotted in Fig. 1(a). Small crack grew discontinuously, but at a cyclic stress intensity below the threshold values for a long crack or a closure-free long crack. The small-crack growth curve deviates from the long crack curve (when $R=0.05$ ) when the cyclic stress intensity is below approximately 10 $\mathrm{MPa} V_{\mathrm{m}}$. Similar test were also done at LNT, and will be presented elsewhere. 10

Growth of Many Cracks. The growth rate of a single surface crack was discontinuous largely because of its interaction with the grain structure. To obtain a reasonable constitutive relation for small crack growth, we averaged the growth rates of many cracks growing simultaneously. To produce a large number of cracks in the same sample, we increased the amplitude of the cyclic load, $\Delta \sigma$, to 57 to $1141 \mathrm{MPa}(96 \% \mathrm{sy})$ at RT. As a result, as many as a hundred cracks initiated, and their lengths were simultaneously measured as a function of the cycle number.

Fig. 3(a) plots the growth rates of about 50 cracks against the cyclic stress intensity, 

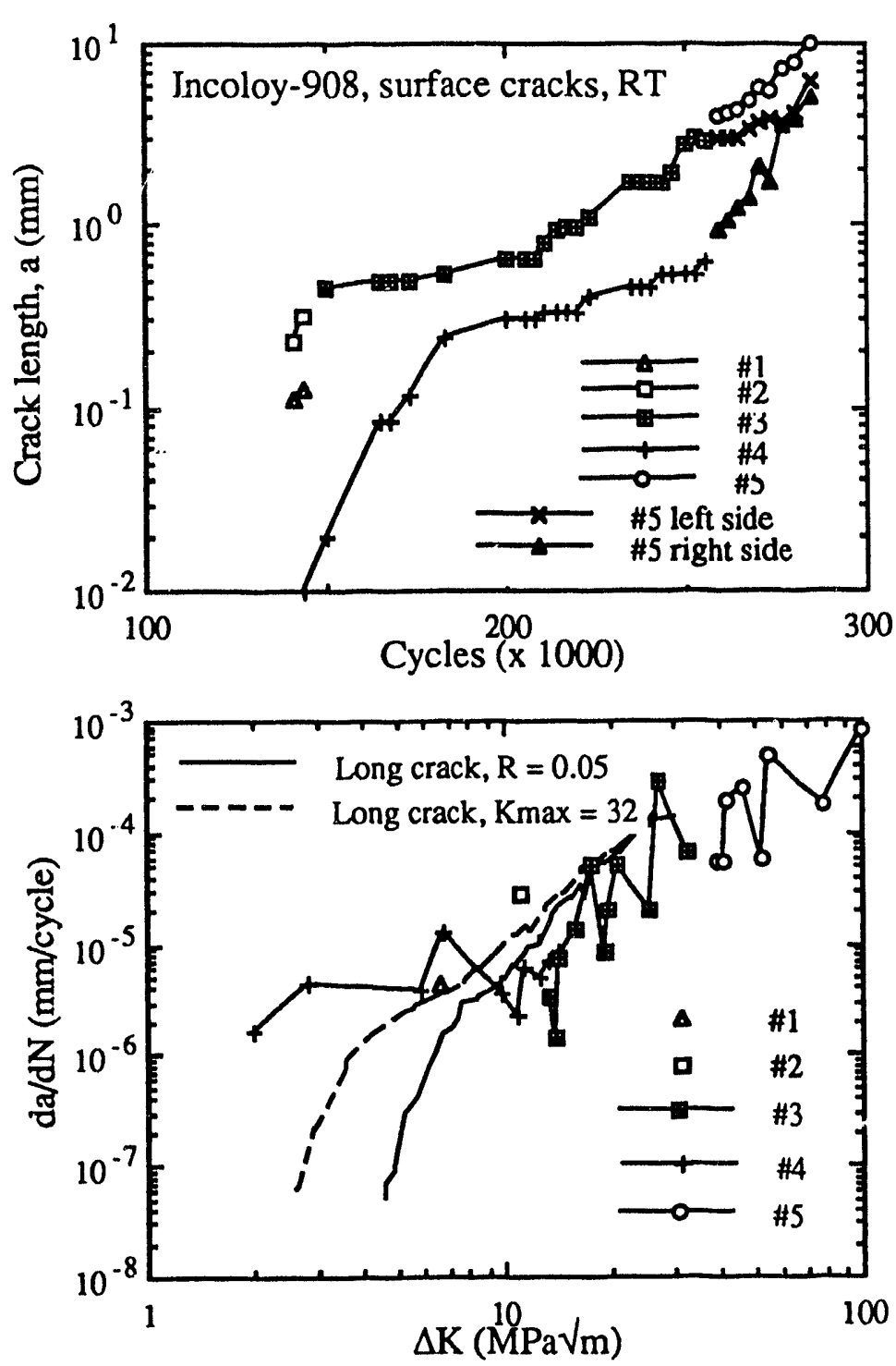

Fig. 2(a): Plots of the length of small surface cracks vs. cycle number in a specimen where the stress oscillated between 38 and $759 \mathrm{MPa}$ at RT.
Fig. 2(b): The growth rate of the surface cracks of Fig. 2(a) vs. the cyclic stress intensity, in comparison with the long crack growth rate plotted in Fig. 1(a).

and compares them to the measured growth rates for the constant $R$ and constant $K_{\max }$ tests. Many cracks became dormant at cyclic stress intensities above the threshold value for long crack propagation at constant $\mathrm{R}$, while some cracks extended at cyclic stress intensities below the threshold value. Crack growth at the cyclic stress intensity below the threshold value 2.8 $\mathrm{MPa} \sqrt{\mathrm{m}}$ for a closure-free long crack could not be studied because $\Delta \sigma$ is so large that even the smallest crack (assumed as inclusion size of $5 \mu \mathrm{m}$ ) was under the cyclic stress intensity larger than $2.8 \mathrm{MPa} V \mathrm{~m}$. The magnitude of scatter in crack growth rate seems larger when the crack sizes are smaller, but all small crack growth rate data points distribute around the curve for the long crack propagation (at the constant $R$ ).

We divided the $\Delta \mathrm{K}$ range in Fig. 3(a) between 3 to $15 \mathrm{MPa} \sqrt{\mathrm{m}}$ into smaller units, and calculated for each unit the average growth rate for all cracks that had cyclic stress intensity within the unit. The average crack growth rates are plotted against the $\Delta \mathrm{K}$ in Fig. 3(b). The average small crack growth curve is near the long crack growth curve at constant $R$. However, at low $\Delta \mathrm{K}$ values, between $3-7 \mathrm{MPa} \sqrt{\mathrm{m}}_{\mathrm{m}}$, the average growth rate of the small cracks that did continue to grow was are significantly higher than the long crack value.

The data in Fig. 3 indicate that the average small crack propagation rate is close to the long crack propagation rate. But the probability of fatigue failure is determined by the fastestgrowing crack, or by the minimum load at which any crack can propagate. For that purpose, the threshold values of $\Delta \sigma$ and $\Delta \mathrm{K}$ for small-crack propagation are determined as a function of crack size.

Threshold $\Delta \sigma_{\text {th }}$ and $\Delta K_{\text {th }}$ versus Crack Length. $\Delta K_{\text {th }}$, the threshold value for crack propagation is usually defined as the $\Delta \mathrm{K}$ when the crack growth rate is below the 5 

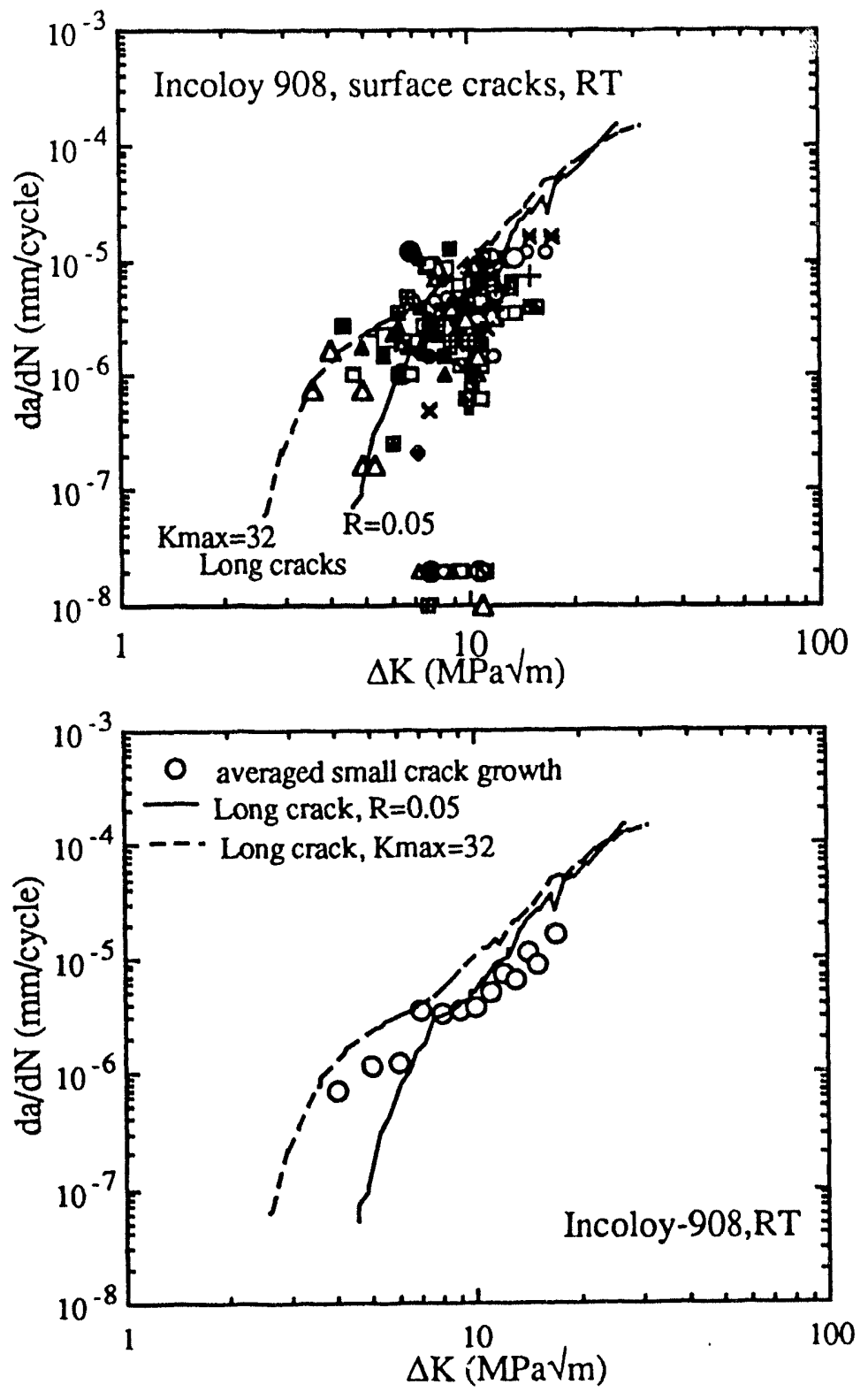

Fig. 3(a): The growth rates of about 50 surface cracks vs. the cyclic stress intensity, in comparison with the long crack growth rates.
Fig. 3(b): The average growth rates of the small cracks in Fig. 3(a) vs. $\Delta \mathrm{K}$.

$x 10^{-5} \mu \mathrm{m} /$ cycle. The small crack length was measured in this study using an optical micro scope with a resolution better than $5 \mu \mathrm{m}$. Therefore, if a small crack has not changed its length (2c) after $10^{5}$ loading cycles of $\Delta \sigma$, the applied $\Delta \mathrm{K}$ is less than $\Delta \mathrm{K}_{\mathrm{th}}$ under this definition. The dependence of $\Delta \mathrm{K}_{\mathrm{th}}$ on $2 \mathrm{c}$ was determined as follows. First, a crack was nucleated on a smooth-surfaced specimen by applying $\Delta \sigma$ slightly higher than the fatigue endurance limit. $\Delta \sigma$ was then decreased to one-half the crack initiation load for $10^{5}$ cycles. If the crack did not extend, $\Delta \sigma$ was raised in increments of less than $10 \%$ for another $10^{5} \mathrm{cy}-$ cles, until the crack began to propagate. The load that is just sufficient to propagate the crack, $\Delta \sigma_{\text {th }}$, was then used with $2 \mathrm{c}$ to calculate $\Delta \mathrm{K}_{\mathrm{th}}$. A load larger than $\Delta \sigma_{\mathrm{th}}$ was then used to grow the crack to a new length. $\Delta \sigma$ was then reduced by half and gradually increased to measure $\Delta K_{\text {th }}$ at the new crack length.

Fig. 4(a) plots $\Delta \mathrm{K}_{\mathrm{th}}$ as a function of $2 \mathrm{c}$ for two tests at LNT. It is seen that when the cracks are very small, $\Delta \mathrm{K}_{\mathrm{th}}$ is below the threshold values for either long cracks or closurefree cracks. When $2 \mathrm{c}$ became larger than about $300 \mu \mathrm{m}, \Delta \mathrm{K}_{\text {th }}$ scattered around the threshold value for a long crack. The scattering was associated with crack interaction with the grain structure.

Fig. $4(\mathrm{~b})$ plots $\Delta \sigma_{\text {th }}$ as a function of $2 c$, obtained from the same tests as Fig. 4(a). When $2 \mathrm{c}$ was small, $\Delta \sigma_{\mathrm{th}}$ was relatively constant and close to the fatigue endurance limit. When the crack size is larger, the cyclic loads required to propagate cracks distribute around the line of the threshold value of cyclic stress intensity for long cracks. 

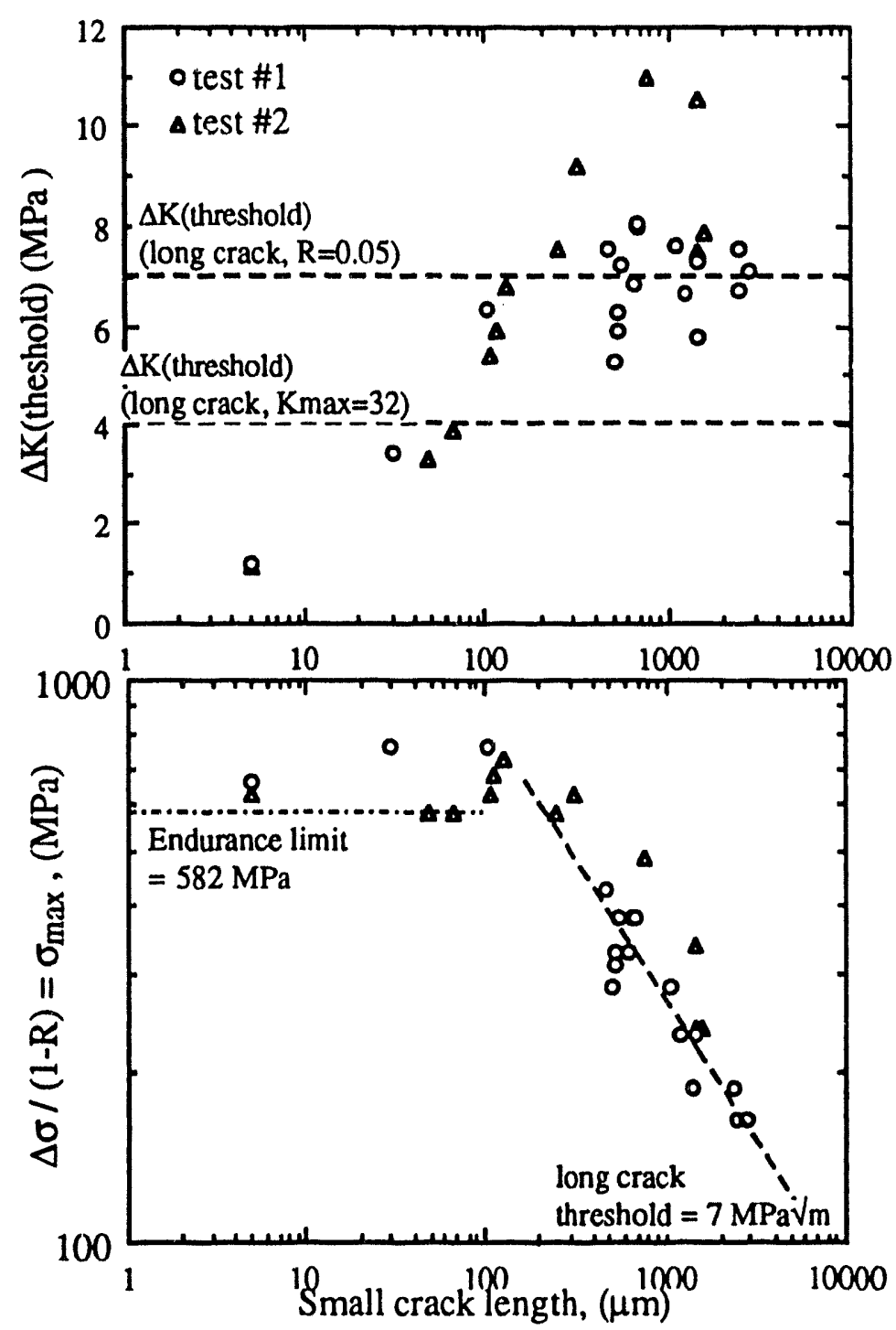

Fig. 4(a): $\Delta \mathrm{K}_{\text {th }}$ of small cracks vs crack length from two tests at LNT.
Fig. 4(b): The threshold cyclic stress for small crack extension vs crack length, obtained from the same tests in Fig. 4(a).

\section{DISCUSSION}

The crack front of a long crack passes through many individual grains. When the applied load is small, the growth rate of a long fatigue crack is not uniform; it varies from grain to grain along the crack front. The commonly used techniques for measuring long crack growth are elastic compliance and DC potential, both of which measure average length over the crack front. The growth of small cracks, however, is dominated by behavior within a local region of the microstructure. The difference between the two crack growth behaviors is, hence, expected, and is statistical in nature.

When a crack is small (roughly, when it is less than 10 times the average grain size), ${ }^{21}$ and the applied load is low (the crack tip plasticity less than grain size), ${ }^{22}$ small cracks grow more rapidly than long cracks at the same $\Delta K$, and small cracks may propagate at cyclic stress intensities below the long crack threshold. This is because the cracks grow in the most favorable sites, the "weak links" in the microstructure. When a smooth-surfaced Incoloy-908 specimen is cyclically stressed, inclusions and other defects act as small "cracks"; the some of them have neighboring grains that are oriented for easy plastic deformation, and nucleate small cracks that begin to grow. As a small crack grows, it samples grains that are less favorably oriented for growth than the initial ones, and the cyclic stress intensity required to maintain crack growth increases. This is a major reason that threshold cyclic stress intensity increases with crack length, as shown in Fig. 4(a). Excessive plasticity and the absence of crack closure also affect small crack propagation. ${ }^{10}$ Both contribute to the trends shown in Figs. 4(a) and (b). 
No matter what mechanisms control the anomalous growth of small crack in Incoloy 908 , the experimental results suggest a method for estimating the rate of small crack propagation at $4.2 \mathrm{~K}$. When either (1) the size of a crack is larger than several times the average grain size or (2) the crack tip plastic zone is larger than grain size, the crack behaves as a long crack; its growth rate obeys the constitutive relations determined from the long-crack growth tests at $4.2 \mathrm{~K}$, and is bounded by tests at constant $\Delta \mathrm{K}_{\mathrm{ma}}$. If neither condition (1) nor condition (2) is satisfied, a small crack does not grow when the applied stress is less than the fatigue endurance limit that can be determined at $4.2 \mathrm{~K}$ with ground and polished specimens. The results suggest that the threshold stress intensity, $\Delta \mathrm{K}_{\mathrm{th}}$, is not a very meaningful number, and, certainly, is not a reliable design parameter value, when short cracks are present. However, the values of $\Delta \sigma$ taht are required to raise $\Delta \mathrm{K}$ to near $\Delta \mathrm{K}_{\mathrm{th}}$ for small cracks in a small-grained material are very high. Hence, a design that maintains loads below the smoothsample fatigue limit is reasonably safe, and even greater design safety can be ensured by assuming that a crack is present and designing to an extension of the Paris Law at $4.2 \mathrm{~K}$.

\section{ACKNOWLEDGMENT}

This work was supported by the Director, Office of Energy Research, Office of Fusion Energy, Development and Technology Division of the United States Department of Energy, under Contract No. DEAC03-76SF00098.

\section{REFERENCES}

1. M.M. Morra, R.G. Ballinger and I.S. Hwang, Metall. Trans. A, Vol 23A, pp. 3177-3192, 1992.

2. The Behaviour of Short Fatigue Cracks, K.J. Miller and E.R. de los Rios, eds., Mechanical Engineering Publications Limited, London, 1986.

3. Fatigue Engng Mater. Structures, 1991, vol. 14, no. 2/3, special issue on International Conference on Short Fatigue Cracks, The European Structural Integrity Society, December 10-14, 1990, Sheffield, U.K.

4. Small Fatigue Cracks, R.O. Ritchie and J. Lankford, eds., Metallurgical Society, Inc., Pennsylvania 15086, 1986.

5. R.O. Ritchie and J. Lankford, in Small Fatigue Cracks, R.O. Ritchie and J. Lankford, eds., Metallurgical Society, Inc., Pennsylvania 15086, 1986, pp. 1-5.

6. K.J. Miller, Fatigue Engng Mater. Structures, vol. 10, pp. 93-113, 1987.

7. S. Suresh, and R.O. Ritchie: Int. Met. Rev., vol. 29, pp 445-476, 1984.

8. Z. Mei and J.W. Morris, Jr., Metall. Trans. A, vol. 24A, pp. 689-700, :993.

9. W.A. Herman, R.W. Hertzberg, and R. Jaccard: Fatigue Engng Mater. Structures, vol. 11, pp. 303$320,1988$.

10. Z. Mei and J.W. Morris, Jr., Metall. Trans. $A$, to be submitted.

11. I.S. Hwang, R.G. Ballinger, M.M. Morra and M.M. Steeves, Advances in Cryogenic Engineering, vol. 38A, pp 1-10, 1991.

12. Annual Book of ASTM Standards, E647-83, ASTM, Philadelphia, PA, 1983, pp. 739-759.

13. Metals Handbook, 9th ed., ASM, Metals Park, OH, 1985, vol. 8, pp. 386-402.

14. J.C. Newman, Jr. and I.S. Raju, Eng. Fract. Mech., 1981, vol. 15, pp. 185-192.

15. P.K. Liaw and W.A. Logsdon, Acla. Metall., 1988, vol. 36, pp. 1731-1744.

16. T. Yokobori, S. Konosu, and A.T. Yokobori, Jr., Proceedings International Conference of Fracture, vol. 1, Pergamon Press, New York, 1978, p.665.

17. S. Suresh and R.O. Ritchie in Fatigue Crack Growth Threshold: Concepts, D.L. Davidson and S. Suresh, eds., TMS-AIME, Warrendale, PA, 1984, pp,. 227-61.

18. S. Suresh, Metall. Trans. A, 1983, vol. 14, pp. 2375-2385.

19. B.A. Bilby, G.E. Cardew, and I.C. Howard, Eracture 1977, D.M.R. Taplin, ed., Univ. of Waterloo Press, 1977, vol. 3, pp. 197-200.

20. A.A. Khrapkov, Int. J. Fract. Mech., 1971, vol. 7, pp. 373-382.

21. D. Taylor and J.F. Knott, Fatigue Engng. Mater. Struct., 1981, vol. 4, pp. 147-55.

22. J. Lankford and D.L. Davidson, in Small Fatigue Cracks, R.O. Ritchic and J. Lankford, eds., Metallurgical Society, Inc., Pennsylvania 15086, 1986, pp. 51-71. 

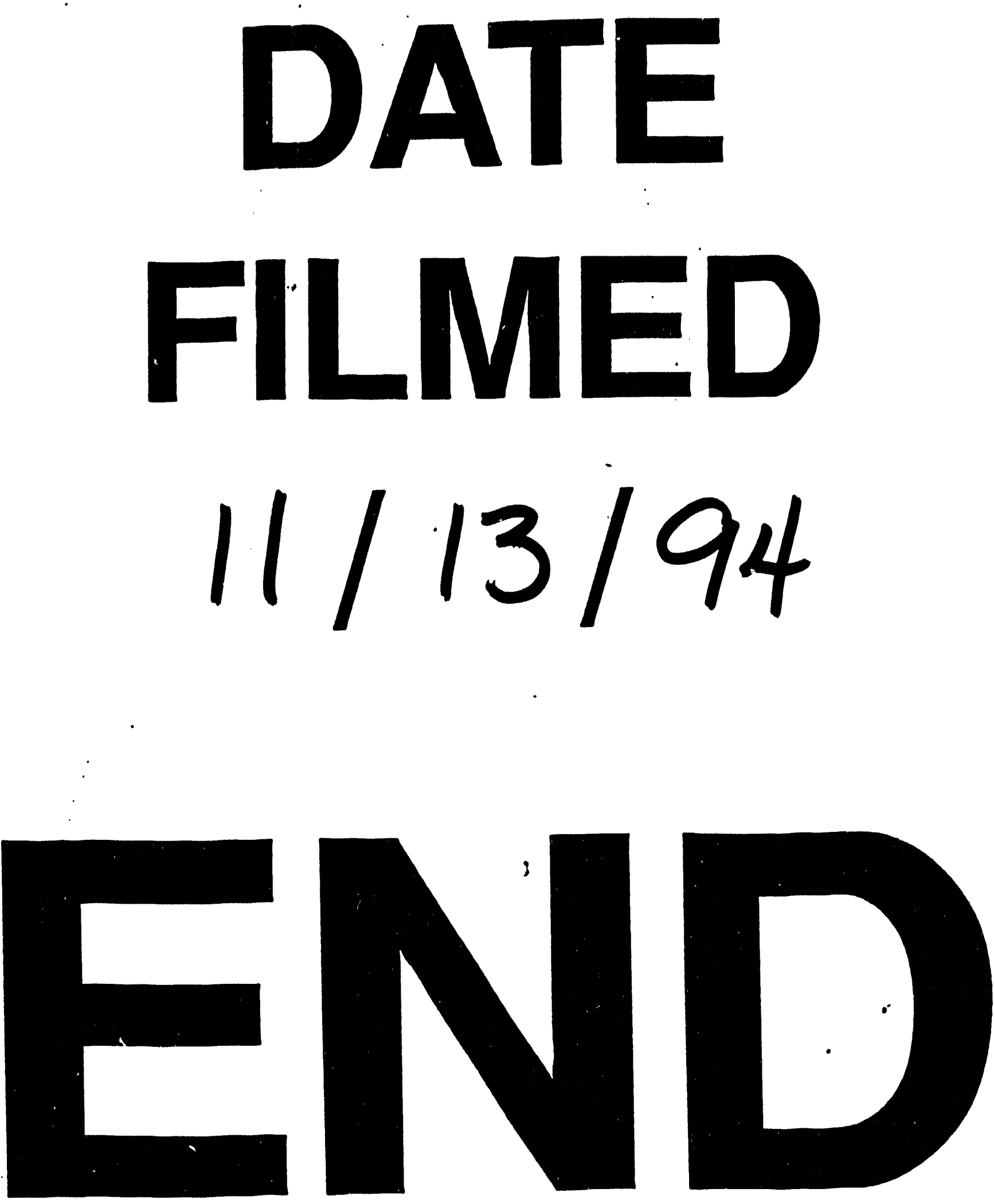


$$
-\ldots
$$

